\title{
Besine özgü immünoglobulin G bazlı eliminasyon diyetlerinin ă̆ırlık kaybına etkisi
}

\author{
Şeyma AKBULUT ${ }^{\mathrm{a}}$, Müveddet Emel ALPHAN ${ }^{\mathrm{b}}$
}

\section{ÖZET}

Beslenme yaşamın her döneminde sağlığın temelini oluşturmaktadır. Birçok insan beslenmenin sağlığa etkisi olduğunun farkındadır ve bazı beslenme alışkanlıkları besin intoleransı, alerji veya duyarlılık semptomlarına neden olabilir. Bir antijene tekrar tekrar maruz kalmak, alerjik benzeri tepkiler veya aşırı duyarlılıklar oluşturabilir. Besin duyarlılığı İmmünoglobulin G (IgG)'ye bağlı olarak gecikmeli reaksiyon göstererek ortaya çıkar. Vücudumuzun bir besine karşı bağışıklık konusunda problemi varsa, IgG oluşmaya başlar. Bu durum bağırsak fonksiyonlarını, yani sindirim sistemini etkiler ve yenilen besinler, bağışıklık sistemi tarafından yabancı madde olarak algılanabilir. Besinler, en önemli inflamasyon kaynağıdır. Genellikle sağlıklı olduğu öne sürülen bir besin, başka bir kişinin sindiremediği bir besin olabilir ve bu besini tüketmek birçok rahatsızlığa yol açabilir. Besine özgü IgG'nin belirlenmesi, inflamasyondan sorumlu besinin belirlenmesini sağlar ve sadece bu besinden uzak durmak bile bu etkene yönelik bir tedavi oluşturur. Besin duyarlılığı testi, kronik inflamatuar reaksiyonlara yol açabilen besinlerin belirlenmesinde kullanılan bir tanı testidir. Klinik ortamda çıkan test sonuçlarının derecelerine göre eliminasyon diyeti uygulanmaktadır. Duyarlılık olduğu belirlenen bu besinler, derecelerine göre belli bir süre elimine edilmektedir. Gıdalar, potansiyel antijenleri temsil ederler; eğer organizma belli bir besine immün reaksiyon geliştirmişse, her gün tüketilen bu besinler kronik inflamatuar hastalık etkeni olabilir. Obezite de inflamatuar bir hastalıktır ve bu derleme yazısı besin duyarlılığına bağlı eliminasyon diyetinin kilo vermeye ve obeziteye etkisini tartışmak amacıyla yazılmıştır.

Anahtar Kelimeler: Diyet, IgG, inflamasyon, obezite

\section{Effect of nutrient-specific immunoglobulin G-based elimination diets on weight loss}

\begin{abstract}
Nutrition is the baseline of the health for lifetime. Most people are aware of the effect of the nutrition on their health and some eating habits may result in food intolerance, allergy or sensitivity symptoms. Repeated exposure to an antigen can eventually produce allergic-like responses or hyper-sensitivities. Food sensitivity arises depending upon immunoglobulin $\mathrm{G}$ (IgG) as a lagged reaction. If body has an immunity problem for a food, IgG might be developed. It affects the functions of the intestine, and so the digestive system, and as a result, the foods might be perceived as a foreign matter by the immune system. Foods are the most important source of inflammation. A food that is suggested to be healthy might be indigestible for a person and to consume this food might result in a lot of disorders. Identifying the food specific IgG result in identifying the food that is responsible for the inflammation and just avoiding this specific food provide the treatment for this factor. Food sensitivity test is a diagnostic test that identifies the foods, which cause chronical inflammatory reactions. According to the degrees of the results of the clinical tests, elimination diet is carried out. The foods that are identified to be sensitive for the person are eliminated for a certain amount of time according to their degrees. Foods represent potential antigens, so, if an organism has developed immune reaction against a food, daily consumption of this food might be a factor of a chronic inflammatory disease. Obesity is also an inflammatory disease and this review paper has been written to discuss the effect of elimination diet that depends on food sensitivity on weight-loss and obesity.
\end{abstract}

Key Words: Diet, IgG, inflammation, obesity

Geliş Tarihi:06.03.2020 Kabul Tarihi: 02.06.2020

${ }^{a}$ Asist Wellness Center, Yorktest Turkey, İstanbul, Türkiye, e-posta: seyma.akbulut94@gmail.com ORCID: 0000-0002-1050-825X 'İ̀stanbul Atlas Üniversitesi, Sağllk Bilimleri Fakültesi, Beslenme ve Diyetetik Bölümü, İstanbul, Türkiye, e-posta: emel_alphan@yahoo.com ORCID: 0000-0002-9702-1881

Sorumlu Yazar/Correspondence: Seyma Akbulutｅ-mail: seyma.akbulut94@gmail.com

Atıf: Akbulut Ş, Alphan ME. Besine özgü immünoglobulin G bazlı eliminasyon diyetlerinin ağırlık kaybına etkisi. Sağlık ve Yaşam Bilimleri Dergisi 2020;2(1):11-15.

Citation: Akbulut S, Alphan ME. Effect of nutrient-specific 1mmunoglobulin G-based elimination diets on weight loss. Journal of Health and Life Science 2020;2(1):11-15. 


\section{GíRIŞ}

Beslenme; yaşamın devam ettirilmesi, büyüme ve gelişme, sağlığın iyileştirilmesi, korunması ve geliştirilmesi, yaşam kalitesinin iyileştirilmesi, üretkenliğin sağlanması için ihtiyaç duyulan besin ögeleri ile biyoaktif bileşenleri sağlayan besinlerin tüketilerek vücutta kullanılmasıdır. ${ }^{1}$ Bireyler, yaş, cinsiyet, aktivite, metabolizma, aile öyküleri, hastalıkları, sağlık sorunları, yaşam şekli ve beğenileri gibi çeşitli yönlerden farklılıklar göstermektedir. Bu yüzden genel ilkeler doğrultusunda planlanacak olan beslenme örüntüsü, mutlaka bireye özgü olmalıdır. ${ }^{2}$ Diyet, bağırsak durumunu iyileştirmede önemli bir etkendir ve gıda bazlı IgG antikorları ile ölçülen besin intoleransları, bağırsak hasarının meydana geldiğini ve vücutta inflamasyona yol açtığını gösterebilir. $\mathrm{Bu}$ reaksiyonlar negatif bir semptom sarmalına neden olarak bütünsel bir yaklaşımla çözüm bulmayı gerekli kılar. Optimal bir diyet, besine karşı gelişen reaksiyonları da dikkate alarak bireyselleştirilmiş bir yaklaşım gerektirir. $^{3}$

Dünya Sağlık Örgütü (DSÖ) fazla kilolu olma ve obeziteyi sağlığa zarar verebilecek anormal veya aşırı miktarda yağ birikimi olarak tanımlamaktadır. ${ }^{4}$ Beden Kütle İndeksi (BKI), fazla kilo ve obeziteyi tanımlamak için kullanılan yaygın bir tarama aracıdır. ${ }^{5}$ Dünya çapında fazla kiloluluk prevalansı $\left(\mathrm{BKI} \geq 25 \mathrm{~kg} / \mathrm{m}^{2}\right)$ ve obezite $\left(\mathrm{BKI} \geq 30 \mathrm{~kg} / \mathrm{m}^{2}\right)$ son otuz yılda \%27'nin üzerinde artmış ve etkilenen bireylerin sayısı yaklaşık 2.1 milyar olmuştur. ${ }^{6}$ DSÖ verilerine göre; obezite dünya çapında 1975 'ten beri neredeyse üç katına çıkmıştır. 2016 yılında, 18 yaş ve üstü 1.9 milyar bireyin fazla kilolu (\%39) ve bunun 650 milyondan fazlasının obez (\%13) olduğu bildirilmiştir. Obezite önlenebilir inflamatuar bir hastalıktır. ${ }^{4}$ Yapılan çalışmalara göre, kronik hastalık ve buna bağlı mortalite riskinin oluşmaması için fazla kilolar verilmeli ve obezitenin önüne geçilmelidir. ${ }^{7-10}$ Obezite günümüzde oldukça yaygın olan inflamatuar bir hastalıktır ve bu derleme yazısı besin duyarlılığına bağlı eliminasyon diyetinin kilo vermeye ve obeziteye etkisini tartışmak amacıyla yazılmıştır.

\section{Besin Duyarlılığı}

Besin duyarlılığı, IgG'ye bağlı olarak gecikmeli reaksiyon göstererek ortaya çıkar. Tip III aşı11 duyarlılık reaksiyonları olarak da tanımlanabilir. Tip III aşırı duyarlılık reaksiyonları, immünoglobulinlerden IgG veya IgM'nin, dolaşan bağışıklık komplekslerinin oluşumuna yol açan çözünür bir antijen ile etkileşimi ile başlatılır. Tipik olarak tip III reaksiyonlar, immünizasyonun bir yan etkisi olarak veya çeşitli otoimmün bozukluklarda yaygın olarak görülen bağışıklık sisteminin homoeostatik dengesindeki bir rahatsılığın sonucu olarak oluşabilir. Genelleştirilmiş tip III reaksiyonlar, büyük miktarlarda antijenin kan dolaşımına girmesinden birkaç gün sonra ortaya çıkar. ${ }^{11}$
Antikorlar, anne sütüyle bebeğe geçebilir veya zaman içerisinde de oluşabilir. IgG antikorları adaptif immün sistemin bir parçasıdır. Bu antikorlar, bir antijen ile temas ettiğinde inflamasyon, reaksiyonu tetikler. Vücudumuzun bir besine karşı bağışıklık konusunda problemi varsa, IgG oluşmaya başlar. $\mathrm{Bu}$ durum bağırsak fonksiyonlarını, yani sindirim sistemini etkiler ve yenilen besinler, bağışıklık sistemi tarafindan yabancı madde olarak algılanabilir. Besinler, en önemli inflamasyon kaynağıdır. Çeşitli besinlere karşı IgG antikorları gözlenmiştir. ${ }^{2}$ Genellikle sağlıklı olduğu öne sürülen bir besin, başka bir kişinin sindiremediği bir besin olabilir ve bu besini tüketmek birçok rahatsızlığa yol açabilir. ${ }^{12}$ Besinler, potansiyel antijenleri temsil ederler; eğer organizma belli bir besine immün reaksiyon geliştirmişse, her gün tüketilen bu besinin kronik inflamatuar hastalık etkeni olacağı açıktır. Bağışıklık sisteminin kişilere göre değişen besinlere tepki vermesinden oluşan inflamasyon, farklı hastalıklara neden olabilir. Besine özgü IgG'nin belirlenmesi, inflamasyondan sorumlu besinin belirlenmesini sağlar ve sadece bu besinden uzak durmak bile bu etkene yönelik bir tedavi oluşturur. Obezite gibi inflamatuar hastalıklarda besine özgü IgG'nin belirlenmesi önerilebilir. Besin duyarlılığına bağlı alerjik reaksiyonlar günümüzde en çok sağlık sorununa sebep olan faktörlerdendir. ${ }^{2}$ İngiliz Alerji Vakfı'nın tahminine göre nüfusun \%45'i besin duyarlılı̆̆ına bağlı sağlık sorunları yaşamaktadırlar. ${ }^{13}$

\section{Besin Duyarlılığı Testi}

Besin duyarlılı̆g 1 testi, kronik inflamatuar reaksiyonlara yol açabilen besinlerin belirlenmesinde kullanılan bir tanı testidir. Bu test ile besinlere karşı vücutta oluşan IgG antikorları, besine özel tüm alt gruplarla birlikte tespit edilmektedir. ${ }^{2}$ IgG'nin saptanması ve nicelendirilmesi, göreceli olarak kolay bir görevdir ve enzime bağlı bir immünosorban testi (ELISA) kullanılarak gerçekleştirilebilir. Ayrıca Ig alt sınıfi ve derecesi daha sonra ELISA ile değerlendirilebilir. IgG laboratuvar test sonuçları klinik ortamda alınmalıdır. Bu testte çıkan sonuçların derecelerine göre eliminasyon diyeti uygulanmaktadır. Duyarlılık olduğu belirlenen bu besinler, derecelerine göre belli bir süre elimine edilmektedir. ${ }^{11}$

IgG besin antikorlarının besin intoleransına aracılık etmemesi ile ilgili rolü konusunda tartışmalar devam etmektedir. $\mathrm{Bu}$ antikorların serum konsantrasyonlarının ölçümü, bazı laboratuvarlar tarafindan diyet için bir rehber olarak kullanılmıştır ve halen kullanılmaktadır. ${ }^{14}$ Uzman toplumlar ve gıda alerjisi ile ilgili yönergeler, bu testlerin kullanımına ilişkin kanıtların eksik olduğunu belirtmektedirler; IgG besin antikorlarının varlığının sadece karşılık 
gelen besinlere maruziyeti yansıttığı ve immünolojik toleransı gösterdiği öne sürülmüştür. ${ }^{14-16}$ Ancak bu görüş, IgG bazlı eliminasyon diyetlerinin, klinik çalışmalarda görülen farklı hasta gruplarındaki semptomları iyileştirdiği gösterilerek reddedilmektedir. ${ }^{17,18}$

\section{TARTIŞMA}

Son yıllarda yapılan araştırmalarda obezitenin inflamatuar bir hastalık olduğu sonucuna varılmış, bireylerin ağırlık kaybetmesi ile inflamasyon göstergesi olan hs-CRP'nin azaldığı gösterilmiştir. ${ }^{19,20}$ Aynı zamanda yapılan çalışmalarda, bireylerde hsCRP'nin düşüşünün ağırlık kaybında faydalı olduğu gösterilmiştir. $^{21,22}$ Yapılan bir çalışmada ${ }^{23}$ obez çocukların besinlere özgü IgG antikor değerleri, normal ağırlıktaki çocuklara göre anlamlı derecede daha yüksektir ve bu durumda besine özgü IgG antikorları "düşük dereceli sistemik inflamasyonla sıkı bir şekilde ilişkilidir" denilmektedir. CRP düzeyleri ile IgG antikorları arasındaki korelasyon, besine özgü IgG bazlı eliminasyon diyetinin ağırlık kaybına etkisi olduğunu düşündürtmektedir.

Obez kişilerde bulunan IgG antikorlarının "açlık hormonu" ghrelin'e, obez olmayanlara kiyasla daha fazla bağlandığı gözlenmiştir. Artan iştah ve yeme isteklerine, kısmen de olsa ghrelin'in oreksijenik (iştah açıcı) etkisini arttıran dolaşımdaki IgG'nin aracılık edebileceği görülmektedir. ${ }^{24} \mathrm{Ek}$ olarak, kronik inflamasyon, leptin direnci olarak adlandırılan ve beynin leptin hormonunun iştah baskılayıcı mesajını alma işlevine zarar vererek yemek yemeye devam etmeye sebep olmaktadır. ${ }^{25}$ Diyetteki yağ fazlalığının, iştah ve termogenez'deki rolü bilinen hipotalamus $^{26}$ üzerinde inflamatuar etkileri olduğu da kanıtlanmıştır. ${ }^{27}$ Gerçekten de obezite; diyet, çevresel ve genetik faktörlerden etkilendiği bilinen bağırsakbeyin eksenindeki rahatsılıklar ve hipotalamik inflamasyon ile ilişkilidir. $^{28}$

Cox ve ark. $^{29}$ bağırsak mikrobiyotasını iyileştiren müdahaleler yoluyla bağırsak geçirgenliğinin azaltılması, bağışıklık sisteminin aktivasyonu ve buna bağlı inflamatuar yanıtın azaltılmasının, obezite ve obezite ile ilişskili hastalıkların ele alınmasında önemli bir strateji olabileceğini öne sürmektedirler.

Yapılan başka bir çalışmada, hipotiroidizmi olan denekler arasında besine karşı intoleransın daha fazla olduğu gösterilmiştir. Hipotiroidizmin ayrıca, buğdaya karşı oluşan IgG ile ve glutene karşı oluşan IgG ile önemli derecede korele olduğu gözlenmiştir. Tiroit bezinin az çalışması, vücutta ve metabolizmada genel bir yavaşlamaya neden olur. Bu durumun ise, ağırlık kaybını zorlaştırdığ 1 bilinmektedir. ${ }^{30,31}$

İki bin on iki yılında, Lewis ve ark. ${ }^{32}$ tarafından immünolojik olarak reaktif yiyecekleri aşırı kilolu kişilerin diyetlerinden çıkarmanın etkilerini inceleyen bir çalışma yayınlandı. Bu çalışmada sadece ağırlıkta oluşan değişimler değil; vücut kompozisyonu, kan basıncı, kalp atışı ile yaşam kalitesinin fiziksel ve zihinsel ölçütleri olan dayanıklılık, bedensel ağrı ve genel sağlık ölçümleri de yapıldı. Çalışmada aşırı kilolu olan 120 deneğe gidaya özgü IgG antikor testi sonuçlarına göre eliminasyon diyeti uygulandı ve denekler 90 gün boyunca tüm reaktif besinleri diyetlerinden elimine ettiler. Katılımcılar, bu 90 günlük süre boyunca ortalama beş $\mathrm{kg}$ verdiler ve bel çevreleri ortalama sekiz $\mathrm{cm}$ inceldi. Vücut kompozisyonlarındaki olumlu değişikliklere ilave olarak diyastolik kan basınçlarında önemli azalmalar görüldü, yaşam kaliteleri fiziksel ve mental açıdan arttığı belirlendi. Kronik hastalıkların bir dizi farklı yatkınlığı içeren çok faktörlü olması muhtemeldir, ancak herhangi bir faktörün etkisinin derecesinin de kişiden kişiye değişebildiği gözlenmiştir.

Yapılan başka bir çalışmada ise, irritabl barsak sendromu (IBS) dahil olmak üzere gastrointestinal semptomların prevalansının yüksek olduğu bildirilen ve morbid obez olan hastalarda $\mathrm{IgG}$ antikorları ölçülmüştür. ${ }^{33-35}$ İlginç bir şekilde, IBS ve obezitenin, bağırsak geçirgenliğinin $\operatorname{artmas}^{36,37}$ gibi çeşitli patofizyolojik özelliklere sahiptir, bu da potansiyel olarak besine özgü antikorların oluşmasına neden olabileceğini düşündürtmektedir. Ancak bu çalışma, IBS ve obezite ile, algılanan besin intoleransına karşılık gelen IgG besin antikorları arasında hiçbir ilişki olmadığını göstermektedir. Ayrıca bu çalışmaya göre; IgG antikorlarının, morbid obezite ve gastrointestinal semptomlardan şikayeti olan seçilmemiş bir gruba diyet önerisi verirken kullanmalarını onaylamamaktadır. ${ }^{38}$

BKİye göre fazla kilolu ve obez olan 18-65 yaşları arasındaki yetişkin bireylerle yapılan başka bir çalışmada, IgG bazlı eliminasyon diyetinin tek başına ağırlık kaybına etkisi olmadığı gözlenmiştir. Bu durumun obeziteye sebep olan birçok faktörün olmasından kaynaklandığı düşünülmektedir. ${ }^{39}$

\section{SONUÇ VE ÖNERILER}

Birçok insan beslenme alışkanlıklarının sağlığa etkisi olduğunun farkındadırlar ve bazı beslenme alışkanlıkları besin intoleransı, alerji veya duyarlılık semptomlarina neden olur, bu nedenle reaktif yiyecekleri diyetten çıkarmak faydalı olabilir. ${ }^{33}$ Neden-sonuç ilişkisi kesin olarak kurulamadığı için, IgG testinin besin intoleransı tanısı için tek başına değerlendirilmemesi gerekmektedir. Ancak besine özgü IgG bazlı eliminasyon diyetinin birçok semptomun giderilmesine katkı sağladığı yönündeki çalışmalar da gün geçtikçe artmaktadır. Günümüzde çok sayıda diyet programı olmasına rağmen bu programların hiçbirinde belirli yiyeceklerin, hatta domates ve havuç gibi sağlıklı olarak kabul edilenlerin dahi, aşırı kilolu bireylerde bağışıklık 
sistemi yanıtını tetikleyerek rahatsızlık oluşturabileceği ihtimalini düşünülmemektedir. Burada dikkat edilmesi gereken en önemli nokta, her bir diyet müdahelesinin, kişiye özel IgG testi sonuçlarına göre yapılması gerektiğidir. Eliminasyon diyeti uygulanırken besin öğesi eksikliğine neden olmamak için diyetten çıkarılacak IgG-reaktif besinlerin, reaktif olmayan benzer besinler ile ikame edildiği yeni diyet konsepti, obezite ile mücadelede stratejik olarak önemli bir etkiye sahiptir. ${ }^{12}$ Besin ögesi yetersizliği veya fazlalığına maruz kalmamak için, eliminasyon diyetlerinin diyetisyenler tarafından planlanıp, takip edilmesi gerekmektedir. ${ }^{2}$

Sonuç olarak; besine özgü IgG bazlı eliminasyon diyetiyle inflamasyonun azaldığı ve buna bağlı olarak obezlerde ağırlık kaybına etkisi olduğu ve böylece bu diyetin yaşam kalitesini de artırdığı sonucuna varılmıştır. Ancak besin duyarlılığı testlerinin güvenilir olup olmadığı hala tartışmalıdır. Bu nedenle bu testlerle ilgili daha çok çalışmaya ihtiyaç olduğu düşünülmektedir.

\section{KAYNAKLAR}

1. Türkiye beslenme rehberi TÜBER 2015, T.C. Sağllk Bakanlığ Yayın No:1031, Ankara, 2016. Available at: https://dosyasb.saglik.gov.tr/Eklenti/ 10915,tuber-turkiye-beslenme-rehberipdf.pdf. Accessed January 30,2020.

2. Alphan Tüfekçi EM. Hastalıklarda Beslenme Tedavisi. 2.bask1. Ankara: Hatiboğlu Yayınevi; 2014.

3. Hart GR. Gut microbiota, IgG-guided elimination diet and sports performance. BAOJ Nutriton. 2018;4:2,4:052.

4. World Health Organization (WHO). Obesity and overweight. Available at: https://www.who.int/ news-room/fact-sheets/detail/obesity-andoverweight Accessed February 16, 2018.

5. Kalish VB. Obesity in older adults. Primary Care: Clinics in Office Practice. 2016;43(1):137-144. doi:10.1016/j.pop.2015.10.002.

6. $\mathrm{Ng} \mathrm{M}$, Fleming $\mathrm{T}$, Robinson $\mathrm{M}$, et al. Global, regional, and national prevalence of overweight and obesity in children and adults during 19802013: a systematic analysis for the global burden of disease study 2013. The Lancet. 2014;384(9945):766-781. doi:10.1016/s01406736(14)60460-8.

7. Shah R, Gayat E, Januzzi Jr JL, et al. Body mass index and mortality in acutely decompensated heart failure across the world: a global obesity paradox. J Am Coll Cardiol. 2014;63(8):778-785. doi:10.1016/j.jacc.2013.09.072.

8. Niedziela J, Hudzik B, Niedziela $\mathrm{N}$, et al. The obesity paradox in acute coronary syndrome: a meta-analysis. Eur J Epidemiol. 2014;29(11):801812. doi: 10.1007/s10654-014-9961-9.

9. Carnethon MR, De Chavez PJ, Biggs ML, et al. Association of weight status with mortality in adults with incident diabetes. J Am Med Assoc. 2012;308(6):581-590.

doi:10.1001/jama.2012.9282.
10. Di Angelantonio E, Bhupathiraju ShN, Wormser $\mathrm{D}$, et al. Body-mass index and allcause mortality: individual-participant-data meta-analysis of 239 prospective studies in four continents. The Lancet. 2016;388(10046):776-786. doi:10.1016/S01406736(16)30175-1.

11. Eggleton P. Hypersensitivity: immune complex mediated (type III). eLS. 2013;1-11. doi:10.1002/9780470015902.a0001138.pub3.

12. Hart GR. Food-Specifc IgG guided eliminaton diet; a strategy for weight loss? BAOJ Obesity \& Weight Loss Management. 2017;3:012.

13. Allergy UK. Stolen lives 3. The food allergy and food intolerance report 2007. Available atwww.allergyuk.org/downloads/resources/reports /StolenLives3.pdf Accessed March 7, 2014.

14. Gocki J, Bartuzi Z. Role of immunoglobulin G antibodies in diagnosis of food allergy. Postepy Dermatol Alergol. 2016;33(4):253-256. doi:10.5114/ada.2016.61600.

15. Carr S, Chan E, Lavine E, Moote W. CSACI position statement on the testing of food-specific IgG. Allergy Asthma Clin Immunol. 2012;8(1):12. doi:10.1186/1710-1492-8-12.

16. Boyce JA, Assa'ad A, Burks AW, et al. Guidelines for the diagnosis and management of food allergy in the United States: summary of the NIAID-sponsored expert panel report. J Allergy Clin Immunol. 2010;126(6):1105-1118. doi:10.1016/j.jaci.2010.10.008.

17. Aydinlar EI, Dikmen PY, Tiftikci A, et al. IgGbased elimination diet in migraine plus irritable bowel syndrome. Headache. 2013;53(3):514-525. doi:10.1111/j.1526-4610.2012.02296.x

18. Guo H, Jiang T, Wang J, Chang Y, Guo H, Zhang $\mathrm{W}$. The value of eliminating foods according to food-specific immunoglobulin $G$ antibodies in irritable bowel syndrome with diarrhoea. J Int Med Res. 2012;40(1):204-210. doi:10.1177/ 147323001204000121.

19. Belalcazar LM, Reboussin DM, Haffner SM, et al. A 1-year lifestyle intervention for weight loss in individuals with type 2 diabetes reduces high Creactive protein levels and identifies metabolic predictors of change. Diabetes Care. 2010;33(11):2297-2303. doi:10.2337/dc10-0728.

20. Lin CC, Kardia SL, Li CI, et al. The relationship of high sensitivity C-reactive protein to percent body fat mass, body mass index, waistto-hip ratio, and waist circumference in a Taiwanese population. BMC Public Health. 2010;10(1):1-8. doi:10.1186/1471-2458-10-579.

21. Ebrahimi M, Heidari-Bakavoli AR, Shoeibi S, et al. Association of serum hs-CRP levels with the presence of obesity, diabetes mellitus, and other cardiovascular risk factors. Journal of Clinical Laboratory Analysis. 2016;30(5):672-676. doi:10.1002/jcla.21920.

22. Dev N, Marcus SR. High sensitive C-reactive protein, an independent and early novel inflammatory marker in healthy obese women. $J$ Biomed Res. 2012;23(1):73-77.

23. Wilders-Truschnig $M$, Mannge $H$, Lieners $C$, Gruber H, Marz W. IgG antibodies against food antigens are correlated with inflammation and intima media thickness in obese juveniles. Exp 
Clin Endocrinol Diabetes. 2007;116(04):241-245. doi:10.1055/s-2007-993165.

24. Takagi K, Legrand R, Asakawa A, et al. Antighrelin immunoglobulins modulate ghrelin stability and its orexigenic effect. Nat Commun. 2013;4(1):2685. doi:10.1038/ncomms3685.

25. Zhou Y, Rui L. Leptin signalling and leptin resistance. Frontiers of Medicine. 2013;7(2):207222. doi:10.1007/s11684-013-0263-5.

26. Viggiano E, Mollica MP, Lionetti L, et al. Effects of a high-fat diet enriched in lard or in fish oil on the hypothalamic amp-activated protein kinase and inflammatory mediators. Front Cell Neurosci. 2016;10:150. doi:10.3389/fncel.2016.00150.

27. Monda M, Viggiano AN, Viggiano A, et al. Hyperthermic reactions induced by orexin A: role of the ventromedial hypothalamus. European Journal of Neuroscience. 2005;22(5):1169-1175. doi:10.1111/j.1460-9568.2005.04309.x.

28. Kreutzer C, Peters S, Schulte DM, et al. Hypothalamic inflammation in human obesity is mediated by environmental and genetic factors. Diabetes. 2017;66(9):2407-2415. doi:10.2337/db17-0067.

29. Cox A, West NP, Cripps AW. Obesity, inflammation, and the gut microbiota. Lancet Diabetes Endocrino. 2015;13(3): 207-215. doi:10.1016/S2213-8587(14)70134-2.

30. Lerner A, Jeremias P, Matthias T. Gut-thyroid axis and celiac disease. Endocr Connect. 2017;6(4):R52-R58. doi:10.1530/EC-17-0021.

31. Sun X, Lu L, Yang R, Li Y, Shan L, Wang Y. Increased incidence of thyroid disease in patients with celiac disease: a systematic review and metaanalysis. PLoS One. 2016;11(12):1-13. doi:10.1371/journal.pone.0168708.

32. Lewis J, Woolger JM, Melillo A, et al. Eliminating immunologically-reactive foods from the diet and its effect on body composition and quality of life in overweight persons. Journal of
Obesity \& Weight Loss Therapy. 2012;2(1):1-6. doi:10.4172/2165-7904.1000112.

33. Aasbrenn M, Hogestol I, Eribe I, et al. Prevalence and predictors of irritable bowel syndrome in patients with morbid obesity: a cross-sectional study. BMC Obes. 2017;4(1):1-8. doi:10.1186/s40608-017-0159-z.

34. Pickett-Blakely O. Obesity and irritable bowel syndrome: a comprehensive review. Gastroenterol Hepatol (N Y ). 2014;10(7):411416.

35. Acosta A, Camilleri M. Gastrointestinal morbidity in obesity. Ann N Y Acad Sci. 2014;1311(1):4256. doi:10.1111/nyas. 12385 .

36. Camilleri M, Madsen K, Spiller R, GreenwoodVan MB, Verne GN. Intestinal barrier function in health and gastrointestinal disease. Neurogastroenterol Motil. 2012;24(6):503-512. doi:10.1111/j.1365-2982.2012.01921.x.

37. Moreno-Navarrete JM, Sabater M, Ortega F, Ricart W, Fernandez-Real JM. Circulating zonulin, a marker of intestinal permeability, is increased in association with obesity-associated insulin resistance. PLoS One. 2012;7(5):1-5. doi:10.1371/journal.pone.0037160.

38. Kvehaugen AS, Tveiten D, Farup PG. Is perceived intolerance to milk and wheat associated with the corresponding IgG and IgA food antibodies? A cross sectional study in subjects with morbid obesity and gastrointestinal symptoms. BMC Gastroenterology. 2018;18(1):18. doi:10.1186/s12876-018-0750-x.

39. Neuendorf R, Corn, J, Hanes D, Bradley R. Impact of food immunoglobulin G-Based elimination diet on subsequent food immunoglobulin $\mathrm{G}$ and quality of life in overweight/obese adults. J Altern Complement Med. 2019;25(2):241-248.

doi:10.1089/acm.2018.0310. 